\section{Indirect Measurement of Leaf Area Index in California North Coast Vineyards}

\author{
Lee F. Johnson ${ }^{1}$ \\ Institute for Earth Systems Science and Policy, California State University, \\ Monterey Bay, NASA Ames Research Center, MS242-4, Moffett Field, \\ CA 94035
}

\section{Lars L. Pierce ${ }^{2}$ \\ Institute for Earth Systems Science and Policy, California State University, Monterey Bay, 100 Campus Center, Seaside, CA 93955}

Additional index words. LAI, winegrape, LI-COR Plant Canopy Analyzer, light interception, remote sensing

\begin{abstract}
The performance of the LI-COR LAI-2000 Plant Canopy Analyzer (PCA) for indirect measurement of leaf area index (LAI) was evaluated in vineyards of California's North Coast region. Twelve plots were established, representing vineyards of differing trellis, cultivar, and planting density. Mean LAI ranged from $0.5-$ to $2.25-\mathrm{m}^{2}$ leaf area per $\mathbf{m}^{2}$ ground area by direct measurement (defoliation). Indirect LAI derived by a standard two-azimuth, diagonal-transect measurement protocol was significantly related to direct LAI $\left(r^{2}=0.78, P \leq 0.001\right)$. However, the PCA underestimated direct LAI by about a factor of two. Narrowing the instrument's conical field of view from $148^{\circ}$ to $56^{\circ}$ increased indirect LAI by $13 \%$ to $60 \%$ in vertically trained plots, but still resulted in substantial underestimation of direct values. Use of this PCA protocol in vineyards should therefore be accompanied by direct measurement for calibration purposes.
\end{abstract}

Leaf area index (LAI; one-sided leaf area normalized by ground area) is a common descriptor of vegetation canopy structure that is related to light interception, productivity, and evapotranspiration (Welles and Norman, 1991). Within vineyards, LAI can be used to monitor carbon balance and assess fruit quality potential (Ollat et al., 1998).

A number of methods have been developed for LAI measurement (Welles, 1990). involves physical removal of leaves from the plant and derivation of their cumulative area with an electronic meter. While accurate on a per plant basis, this approach is destructive and labor intensive. Viticulturists often make management decisions on the basis of dormant period pruning weights (prior season's wood production), which are empirically related to LAI (Johnson et al., 2003). Optical instruments such as the LI-2000 Plant Canopy Analyzer (PCA) (LI-COR, Inc., Lincoln, Nebr.) are designed for rapid, nondestructive LAI estimation in agricultural and natural plant canopies.

Remote sensing offers a means to vastly

Received for publication 20 Sept. 2002. Accepted for publication 16Apr. 2003. We gratefully acknowledge cooperation of the Robert Mondavi Winery, Oakville, Calif., particularly that of vineyard technical manager Daniel Bosch. The study was sponsored by NASA's Office of Earth Science, through grants NAG1399020 to L.F.J., and NAG5-6529 to L.L.P. Use of trade names is for informational use only.

${ }^{1}$ Senior Research Scientist, Adjunct Faculty Member; to whom reprint requests should be addressed.E-mail address: ljohnson@mail.arc.nasa.gov

${ }^{2}$ Associate Professor. The most direct measure, as used in this study, increase spatial coverage with respect to that achievable by ground-based methods alone. Airborne imagery has been used to map relative LAI differences within individual vineyards (Hall et al., 2002; Johnson et al., 2001; Wildman et al., 1983). Commercial winegrape growers in California's North Coast viticultural region (Napa, Sonoma, Lake, and Mendocino counties) are using digital imagery for various purposes, such as harvest preparation, vineyard redevelopment, and identification of problems related to irrigation, nutrition, disease, and pest infestation (Carothers, 2000). More recently, multispectral aircraft and satellite imagery has been used to map vineyard canopy density in absolute terms as leaf area $\left(\mathrm{m}^{2}\right)$ per vine or per meter of row (Dobrowski et al., 2002; Johnson et al., 2003). For greatest accuracy, such maps require collection of supporting, ground-based LAI data.

Prior studies have used several measurement protocols to estimate vineyard LAI with varying degrees of success (Grantz and Williams, 1993; Ollat et al., 1998; Patakas and Noitsakis, 1999; Sommer and Lang, 1994). The current study was conducted to evaluate use of a standard two-azimuth, diagonal-transect, PCA protocol for LAI estimation in commercial winegrape vineyards of California's North Coast. A "whole farm" research approach (National Research Council, 1997) was pursued whereby LAI differences were driven by actual farming practices and grower choices concerning planting density, trellis system, and cultivar.

\section{Materials and Methods}

Study sites. Study plots were located within the Tokalon and Huichica "ranches" of the Robert Mondavi Winery (Oakville, Calif.). The 500-ha Tokalon ranch is located in the Napa Valley (lat. $38^{\circ} 25^{\prime} \mathrm{N}$, long. $122^{\circ} 25^{\prime} \mathrm{W}$ ) and planted mainly to red grape cultivars on is located $22 \mathrm{~km}$ south-southeast of Tokalon in the Carneros region (lat. $38^{\circ} 14^{\top} \mathrm{N}$, long. $\left.122^{\circ} 22^{\prime} \mathrm{W}\right)$. Huichica produces red and white grape cultivars on clay soils with variable topography.

Six plots were established within separate vineyards at each ranch (Table 1). Of these 12 plots, seven plot canopies were vertically trained, one was a split canopy, and five were untrained. Vertical canopy systems essentially produce "walls" of leaves and may be thought of as having an "I" cross-section, while split canopies have a "Y" cross-section (Fig. 1). Plot centers were situated at least $15 \mathrm{~m}$ from the nearest edge to avoid contamination by light scattered laterally into the sensor field-of-view from outside the vineyard.

Indirect LAI. The PCA calculates LAI from observations made with a "fish eye" optical sensor as fully described in Welles and Norman (1991) and LI-COR (1992). Briefly, the clay loam soils. The 300-ha Huichica ranch

Table 1. Study plots located at Robert Mondavi Vineyards (Oakville, Calif.). Leaf area index (LAI) by direct measurement (defoliation) also shown.

\begin{tabular}{|c|c|c|c|c|c|c|}
\hline Plot & Trellis $^{\mathrm{z}}$ & Cultivar $^{\mathrm{y}}$ & $\begin{array}{c}\text { Age } \\
\text { (years) }\end{array}$ & $\begin{array}{c}\text { Vine space } \\
(\mathrm{m})\end{array}$ & $\begin{array}{c}\text { Row space } \\
\text { (m) }\end{array}$ & $\begin{array}{c}\mathrm{LAI} \\
\left(\mathrm{m}^{2} \cdot \mathrm{m}^{-2}\right)\end{array}$ \\
\hline \multicolumn{7}{|c|}{ Huichica Ranch } \\
\hline 1 & V & $\mathrm{PN}$ & 11 & 1.5 & 2.4 & 0.66 \\
\hline 2 & V & $\mathrm{Ch}$ & 6 & 1.2 & 1.2 & 2.25 \\
\hline 3 & V & $\mathrm{Ch}$ & 11 & 1.5 & 2.1 & 1.66 \\
\hline 4 & V & $\mathrm{Ch}$ & 11 & 1.5 & 2.4 & 1.50 \\
\hline 5 & V & $\mathrm{Ch}$ & 10 & 1.5 & 2.4 & 1.26 \\
\hline 6 & $\mathrm{~V}$ & $\mathrm{PN}$ & 11 & 1.5 & 2.4 & 1.11 \\
\hline \multicolumn{7}{|c|}{ Tokalon Ranch } \\
\hline 7 & $\mathrm{u}$ & $\mathrm{CS}$ & 28 & 1.8 & 3.7 & 0.60 \\
\hline 8 & $\mathrm{u}$ & $\mathrm{CF}$ & 11 & 1.5 & 2.7 & 0.95 \\
\hline 9 & $\mathrm{u}$ & $\mathrm{CF}$ & 21 & 2.4 & 3.7 & 0.96 \\
\hline 10 & $\mathrm{~S}$ & $\mathrm{CS}$ & 10 & 1.8 & 3.0 & 1.72 \\
\hline 11 & $\mathrm{~V}$ & $\mathrm{CS}$ & 10 & 3.0 & 1.8 & 1.59 \\
\hline 12 & $\mathrm{u}$ & SB & 2 & 1.5 & 1.8 & 1.26 \\
\hline
\end{tabular}

'Trellis systems: V (vertical); S (split); u (untrained).

yCultivar: PN ('Pinot Noir'); Ch ('Chardonnay'); CS ('Cabernet Sauvignon'); CF ('Cabernet Franc'); SB ('Sauvignon Blanc'). 
instrument has a $148^{\circ}$ conical field-of-view. Diffuse sunlight is measured by five concentric detector rings associated with the following zenith angles, where $0^{\circ}$ represents the direct upward-view: 0 to $13^{\circ}, 16$ to $28^{\circ}, 32$ to $43^{\circ}$, 47 to $58^{\circ}$, and 61 to $74^{\circ}$. Upward-looking measurements are made both above and below the canopy to determine gap fraction, which is the proportion of sky visible from a given location beneath the canopy. A mathematical model embedded within the LAI-2000 software then uses gap fraction to automatically estimate LAI and other structural parameters (after Miller, 1967).

Atwo-azimuth protocol for PCAuse in heterogeneous row-crop canopy, recommended in the instrument manual, was followed (LICOR, 1992; Welles and Norman, 1991). First, a measurement of ambient light was made with the sensor extended upward and over the top of the canopy at arm's length. Four below-canopy readings were then made along a diagonal transect between rows, with the instrument held a few centimeters above the soil. The first reading was taken directly beneath the vine row. The next three readings were taken one-quarter, one-half, and three-quarters of the distance to the adjoining row centerline along a diagonal transect, with each measurement offset in the along-row direction by $\approx 1 \mathrm{~m}$. This procedure was repeated on a total of four adjoining rows. Mean plot LAI and standard error were then computed by the PCA, based on a total of 16 canopy and four associated ambient readings. No corrections were made for the presence of woody components, trellis, or irrigation structure, all of which would be expected to decrease gap fraction and inflate the indirect LAI estimate.

A physical cap was used to limit the azimuthal field-of-view to $45^{\circ}$, facing away from the operator. Two transects were performed with along-row view azimuth and two with across-row view azimuth. All measurements were made under diffuse light conditions (sun below horizon or obscured by fog) to avoid introducing error due to the presence of sunlit foliage. This sampling approach took $\approx 5 \mathrm{~min}$ perplot to complete. Measurements were made at Huichica on 20 Sept. 2001 and at Tokalon on 27 Sept. 2001.

Direct LAI. Direct LAI measurements were made immediately upon completion of PCA observations. Each plot contained three replications: the center vine and vines abreast of the center vine in adjacent rows. Leaves were removed at the petiole from an estimated proportion of each sample vine as follows. All leaves were removed from vines in two plots (\#1, \#7, Table 1), due to their relatively low amount of leaf area. For the split canopy (plot $\# 10$, Table 1), all leaves were removed from one of the four main cordons $(\approx 25 \%$ of the vine). At the remaining plots, all leaves were removed from either the right or left cordon ( $\approx 50 \%$ per vine).

All excised leaves per plot were immediately transported to a nearby indoor facility where they were weighed on a laboratory balance (Model EK-1200A, A\&D Co., Ltd., Tokyo). A subsample from each vine was

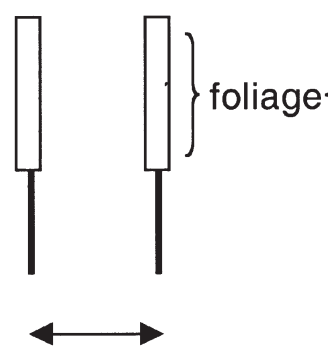

Row spacing

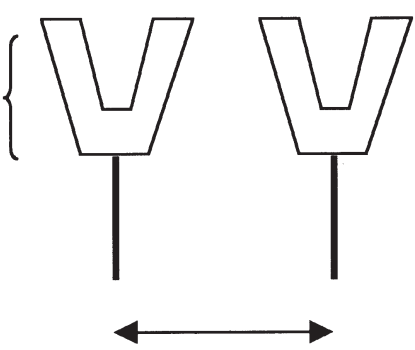

Row spacing

Fig. 1. Idealized cross-section of (left) a vertically shoot positioned canopy and (right) a split canopy.

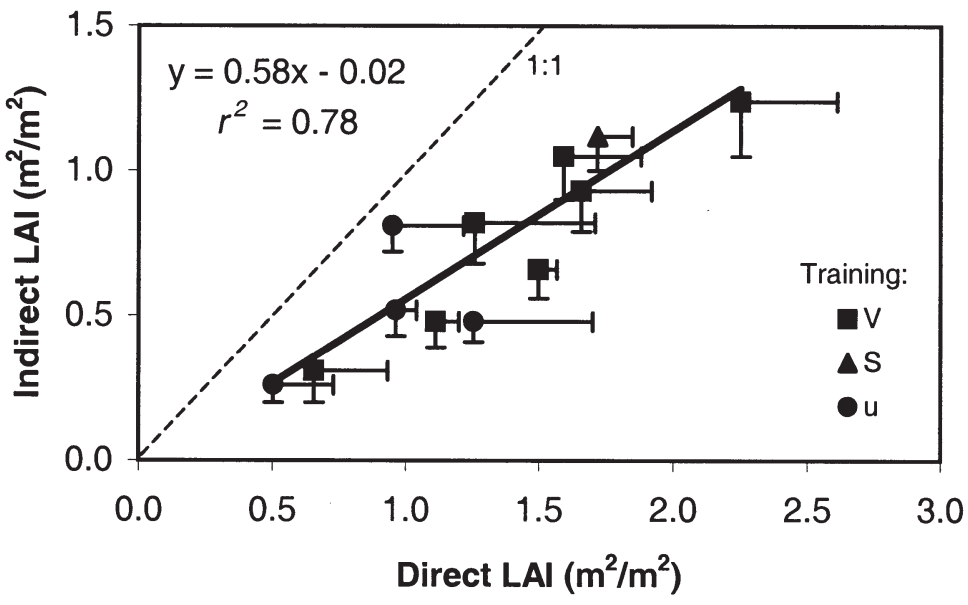

Fig. 2. Mean direct leaf area index (LAI) (measured by defoliation) vs. mean indirect LAI (measured by the Plant Canopy Analyzer using data from all detector rings), for 12 study plots. Canopy types are vertically trained $(\mathrm{V}, \mathbf{\square})$, split $(\mathrm{S}, \mathbf{\Delta})$, and untrained $(\mathrm{u}, \mathbf{O})$. Error bars show 1 standard error. Dashed 1:1 line shown for reference.

weighed, placed in a sealed bag, and stored in a refrigerator at $3^{\circ} \mathrm{C}$. Subsample leaf area was measured within $24 \mathrm{~h}$ on an electronic meter (Model LI-3000, LI-COR, Inc.). Total leaf area $\left(\mathrm{m}^{2}\right)$ per sample vine was calculated as

$$
\mathrm{LA}_{\mathrm{v}}=\mathrm{W}_{\mathrm{t}} \times \mathrm{SLA} / \mathrm{P}
$$

where $\mathrm{W}_{\mathrm{t}}$ is total weight $(\mathrm{g})$ of all leaves removed from vine, SLA is specific leaf area $\left(\mathrm{m}^{2} \cdot \mathrm{g}^{-1}\right)$ of the subsample, and $\mathrm{P}$ is the estimated proportion of leaves $(0.25,0.50$, or 1.0) removed from the vine. The LAI for each sample vine in the study plot was then calculated as

$\mathrm{LAI}_{\mathrm{v}}=\mathrm{LA}_{\mathrm{v}} /($ vine-spacing $\times$ row-spacing $)$;

plot mean LAI and standard error were derived from the $\mathrm{LAI}_{\mathrm{v}}$ of the sample vine replications.

\section{Results and Discussion}

Direct LAI ranged from 0.50 to 2.25 , while indirect LAI ranged from 0.26 to 1.24 . Direct and indirect measurements were positively related ( $\left.r^{2}=0.78, P \leq 0.001\right)$ (Fig. 2), although indirect, PCA-based measurements underestimated LAI by a factor of two. Underestimation of vineyard LAI has been noted in previous PCA studies (Grantz and Williams, 1993; Sommer and Lang, 1994). The PCA computational model assumes that foliage is randomly distributed throughout the canopy.
Table 2. Indirect leaf area index (LAI) for the Huichica plots from unmasked (data from all detector rings used) and masked (data from rings 3-5 omitted) observations of the Plant Canopy Analyzer. Direct LAI shown in Table 1.

\begin{tabular}{lccc}
\hline Plot & $\begin{array}{c}\text { LAI } \\
\text { unmasked }\end{array}$ & $\begin{array}{c}\text { LAI } \\
\text { masked }\end{array}$ & $\begin{array}{c}\text { Percent increase } \\
\text { in LAI, masked } \\
\text { vs. unmasked }\end{array}$ \\
\hline 1 & 0.31 & 0.38 & +22.6 \\
2 & 1.24 & 1.41 & +13.7 \\
3 & 0.93 & 1.26 & +35.5 \\
4 & 0.66 & 0.82 & +24.2 \\
5 & 0.82 & 1.11 & +35.4 \\
6 & 0.48 & 0.77 & +60.4 \\
\hline
\end{tabular}

This assumption is not met in the vineyard where, as is typical of many crops, leaves are grouped along rows with open space between rows. In particular, PCA protocols involving between-row measurements with along-row view direction have been found to underestimate LAI (Ollat et al., 1998), as non-random leaf distribution causes overestimation of gap fraction.

It should be noted that in our data, vine training did not seem to influence the magnitude of LAI underestimation. The PCA was used to sample from two different trellis types as well as untrained vines. Residuals about the Figure 2 regression line showed no marked tendency with respect to training configuration. The major source of underestimation bias is apparently 
the inherent row structure of vineyards.

Prior studies report improved vineyard LAI estimation by exclusion of data from the greater zenith angle detector rings (Watanabe et al., 1997; Grantz and Williams, 1993). That approach was tested here as well. Optical data from the Huichica plots were post-processed with the LI-COR 2000-90 support software to omit data from rings $3-5$ (incidence angles of 32 to $74^{\circ}$ ). This correction increased our estimates of indirect LAIby $13 \%$ to $60 \%$ (Table 2) but still resulted in substantial underestimation of direct LAI.

In summary, the two-azimuth, diagonaltransect protocol recommended by LI-COR (1992) resulted in substantial underestimation of LAI in vertical, split, and untrained vineyard canopies. Indirect LAI estimates made under this PCA protocol, under any of these canopy types, should be accompanied by direct measurement for calibration purposes. Given these calibrations, however, the PCA can then be used by researchers or vineyard managers to rapidly obtain LAI estimates. These data can potentially be used directly, or in combination with remotely sensed imagery, to support canopy and irrigation management decisions affecting grape quality and yield.

\section{Literature Cited}

Carothers, J. 2000. Imagery technology meets vineyard management. Practical Winery and Vineyard, May/June.

Dobrowski, S.Z., S.L. Ustin, and J.A. Wolpert, 2002. Remote estimation of vine canopy density in vertically shoot positioned vineyards: Determining optimal vegetation indices, Austral. J. Grape and Wine Res. 8:117-125.

Grantz, D.A. and L.E. Williams. 1993. An empirical protocol for indirect measurement of leaf area index in grape (Vitis vinifera L.). HortScience 28:777-779.

Hall, A., D.W. Lamb, B. Holzapfel, J. Louis. 2002. Optical remote sensing applications in viticulture - A review. Austral. J. Grape and Wine Res. 8:36-47.

Johnson, L.F., D.E. Roczen, S.K. Youkhana, R.R. Nemani, and D.F. Bosch. 2003. Mapping vineyard leaf area with multispectral satellite imagery. Computers and Electronics in Agr. 38:33-44.

Johnson, L.F., D.F. Bosch, D.C. Williams, and B.M Lobitz. 2001. Remote sensing of vineyard management zones: Implications for wine quality. Appl. Eng. Agr. 17:557-560.

LI-COR. 1992. LAI-2000 plant canopy analyzer operating manual. LI-COR, Lincoln, Nebr. Apr. 1992

Miller, J.B. 1967. A formula for average foliage density. Austral. J. Bot. 15:141-144.
National Research Council. 1997. Precision agriculture in the 21 st century. Natl. Acad. Press, Washington, D.C.

Ollat, N., M. Fermaud, J.P. Tandonnet, and M. Neveux. 1998. Evaluation of an indirect method for leaf area index determination in the vineyard: Combined effects of cultivar, year and training system. Vitis 37(2):73-78.

Patakas, A. and B. Noitsakis. 1999. An indirect method of estimating leaf area index in cordon trained spur pruned grapevines. Scientia Hort. 80:299-305.

Sommer, K.J. and A.R.G. Lang. 1994. Comparative analysis of two indirect methods of measuring leaf area index as applied to minimal and spur pruned grape vines. Austral. J. Plant Physiol. 21:197-206.

Watanabe. J., R.M. Pool, and K.N. Watanabe. 1997. The evaluation of an optical method to estimate leaf area of grapevines. J. Jpn. Soc. Hort. Sci. 66:235-244.

Welles, J.M. and J.M. Norman. 1991. Instrument for indirect measurement of canopy architecture. Agron. J. 83:818-825.

Welles, J.M. 1990. Some indirect methods of estimating canopy structure. Remote Sensing Rev. 5:3143.

Wildman, W., R. Nagaoka, and L. Lider. 1983. Monitoring spread of grape phylloxera by color infrared aerial photography and ground investigation. Amer. J. Enol. Viticult. 34:83-94. 